\title{
Technik und die Folgen
}

\section{Erhard Taverna}

Dr. med., Mitglied der Redaktion

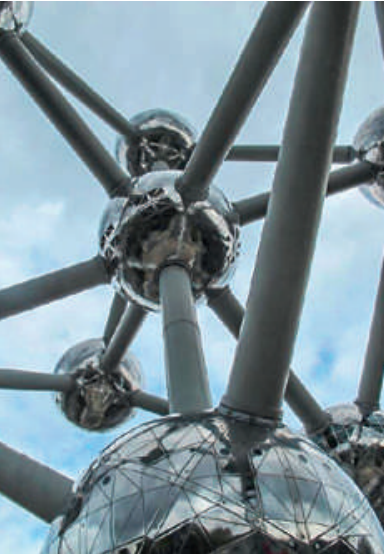

Das Atomium von 1958: Aufbruch in eine strahlende Zukunft.
Dynamik ist eine Eigenschaft der Moderne, die permanente Veränderung unsere einzige Gewissheit. Das technisch Mögliche und Machbare nimmt zu, die weitreichenden Auswirkungen in allen Lebensbereichen sind unbestritten. Damit werden für rationales Handeln Prognosen unentbehrlich und Zukunftsvorsorge für politische Belange an professionelle Risikomanager delegiert.

Zahlreiche Forschungseinrichtungen der Umwelt- und Techniksoziologie beraten Parlamente und Behörden, indem sie versuchen, die möglichen Folgen neuer Technologien abzuschätzen. Ihre Empfehlungen bestimmen die Verteilung von Fördergeldern, beeinflussen Gesetze und Vorschriften und die öffentliche Diskussion, wenn es zum Beispiel um Klimawandel, Energiewende, Stammzellen oder Präimplantationsdiagnostik geht. Keine Technik hat nur positive oder negative Auswirkungen. Zur Abwägung gehören die systematische Erfassung der zu erwartenden Folgen eines Technikeinsatzes und die Beurteilung von Handlungsoptionen aufgrund der Wünschbarkeit. Vor- und Nachteile sollen im Idealfall gemäss nachvollziehbaren und politisch legitimierten Kriterien erfolgen.

Doch mit Sicherheit ins Ungewisse zu gehen, wird nie möglich sein, Fehlentwicklungen sind nicht auszuschliessen, Katastrophen immer möglich. Je naheliegender der Zeithorizont, desto zuverlässiger die Prognose. Die weiter entfernte Zukunft lässt sich nicht verwalten. Dass ein rein wissenschaftlich-rationaler Ansatz, wie ihn der Begriff des Risikomanagements ausdrückt, nicht genügt, zeigen zahlreiche Beispiele wie die unvorhergesehenen Langzeit-Wirkungen von Asbest, FCKW, Kernspaltung, Gentechnik, Motorisierung oder Digitalisierung. Vollends unmöglich ist es, langfristige, soziale Auswirkungen optional-rechnend vorwegzunehmen. Dazu wäre eine Zukunftsethik erforderlich, eine Idee von dem, wer wir sind und was wir wollen, eine Religion, eine Utopie, eine global verbreitete Übereinstimmung anzustrebender Ziele. Zudem wird das Wissenschaftsverständnis paradoxerweise kleiner. Ersatzwissen und Aberglauben nehmen proportional zur Technisierung des Alltags zu. Solange Technologiefolgen als überwiegend angenehm empfunden werden, wird sich die Mehrheit der Konsumenten fatalistisch an das Unvermeidliche gewöhnen. Optimisten gehen davon aus, dass man keine Entwicklung behindern soll, da es der Fortschritt schon richten wird. Der Mensch als Mass aller Dinge ist nur sich selber verpflichtet und trägt damit keine Verantwortung für das, was er ausserhalb seiner Sphäre vorfindet. Wo die Pessimisten sind, ist schwieriger auszumachen. Sind es die, die vor unheilvollen Entwicklungen warnen oder jene, die das Gegebene für schlecht oder unwert genug halten um jedes Wagnis möglicher Verbesserungen auf sich zu nehmen? Etwa die Verheissungen einer Medizin, die den Tod als organische Fehlleistung betrachtet, die Keimbahn manipuliert oder soziale Verhaltenskontrollen ermöglicht.

Im Wissen um das ethische Vakuum hat der Philosoph Hans Jonas (1903-1993) sein Werk Das Prinzip Verantwortung - Versuch einer Ethik für die technologische

Mangels besserer Vorstellungen empfahl Jonas beim Abwägen den Vorrang der schlechten Prognose.

Zivilisation geschrieben [1]. Mangels besserer Vorstellungen empfahl er beim Abwägen den Vorrang der schlechten Prognose. Für unklare Risiken mit weitreichenden möglichen Folgen empfahl er eine «Heuristik der Furcht». Wenn im Übel das zu rettende Gute sichtbar werde, im Unheil das nicht illusionäre überforderte Heil, dann sei die Furcht die erste Pflicht einer Ethik geschichtlicher Verantwortung. Vor den Irrwegen der Macht schütze nur die Ehrfurcht für das, was der Mensch war und ist. Bescheidenheit und Verzicht waren nie populär. Seine Warnung vor der Selbstüberschätzung des Menschen steht nicht auf der Checkliste aktueller Technologiefolgen-Abschätzungs-Institute. Hans Jonas, der bei Heidegger und Bultmann studierte, verfasste ein Standardwerk zur Geschichte der Gnosis. Er erlebte Exil und Krieg und die Schrecken der Schoah. Seine Zeugenschaft und das immense historische Wissen prägen die philosophische Analyse der «Verantwortung», speziell auch der medizinischen Wissenschaften. Sein Denken eröffnet eine Dimension, die weit über ein blosses Risikomanagement hinausreicht. «Die Ehrfurcht allein, indem sie uns ein «Heiliges», das heisst unter keinen Umständen zu Verletzendes enthüllt (und das ist auch ohne positive Religion dem Auge erscheinbar)", so Jonas, "wird uns auch davor schützen, um der Zukunft willen die Gegenwart zu schänden, jene um den Preis dieser kaufen zu wollen.»

1 Jonas H. Das Prinzip Verantwortung. Frankfurt a. M.: Suhrkamp. 1. Aufl.; 1984 . 